Jurnal Keperawatan Silampari

Volume 3, Nomor 1, Desember 2019

e-ISSN: 2581-1975

p-ISSN: 2597-7482

DOI: https://doi.org/10.31539/jks.v3i1.841

\title{
PENGARUH PENYULUHAN IDENTIFIKASI PASIEN DENGAN MENGGUNAKAN MEDIA AUDIOVISUAL TERHADAP PENGETAHUAN PASIEN RAWAT INAP
}

\author{
Roymond H. Simamora \\ Fakultas Keperawatan, Universitas Sumatera Utara \\ roymond_oy@yahoo.com
}

\begin{abstract}
ABSTRAK
Tujuan dari penelitian ini untuk mengetahui pengaruh aplikasi media audiovisual pelaksanaan identifikasi pasien terhadap pengetahuan pasian di rumah sakit Universitas Sumatera Utara Tahun 2019. Penelitian menggunakan pendekatan kuantitatif, dengan metode eksperimen semu, desain one group pre-test-post-test. Hasil penelitian menunjukkan bahwa sebelum dilakukan penyuluhan, 40 orang pasien masuk dalam kategori pengetahuan cukup, dan 80 orang dalam kategori pengetahuan kurang. Setelah dilakukan Penyuluhan menggunakan Media audiovisual dilakukan, diperoleh data bahwa, sebanyak 12 orang pasien masuk dalam Kategori pengetahuan baik, 68 orang dalam kategori pengetahuan cukup, dan 40 orang dalam kategori pengetahuan kurang. Hasil ini menunjukkan bahwa ditemui adanya peningkatan jumlah pasien dalam kategori pengetahuan. Simpulan, ada pengaruh penyuluhan yang diberikan dengan pengguaan media audiovisual terhadap peningkatan jumlah pasien dalam kategori pengetahuan.
\end{abstract}

Kata Kunci: Identifikasi Pasien, Media Audiovisual, Penyuluhan

\section{ABSTRACT}

The purpose of this study was to determine the effect of audiovisual media application of patient identification implementation on patient knowledge at the University of North Sumatra Hospital in 2019. The study used a quantitative approach, with quasiexperimental methods, one group pre-test-post-test design. The results showed that before counseling, 40 patients included in the category of sufficient knowledge, and 80 people in the category of insufficient knowledge. After counseling using audiovisual media, data obtained that, as many as 12 patients included in the category of good knowledge, 68 people in the category of sufficient knowledge, and 40 people in the category of lack of knowledge. These results indicate that there was an increase in the number of patients in the knowledge category. Conclusion, there is an influence of counseling given by the use of audiovisual media to increase the number of patients in the knowledge category.

Keywords: Patient Identification, Audiovisual Media, Counseling 


\section{PENDAHULUAN}

Keselamatan Pasien (patient safety) merupakan sesuatu yang jauh lebih penting dari pada sekedar efisiensi pelayanan. Perilaku perawat dengan kemampuan perawat sangat berperan penting dalam pelaksanaan keselamatan pasien. Perilaku yang tidak aman, lupa, kurangnya perhatian/motivasi, kecerobohan, tidak teliti dan kemampuan yang tidak memperdulikan dan menjaga keselamatan pasien berisiko untuk terjadinya kesalahan dan akan mengakibatkan cedera pada pasien, berupa Near Miss (Kejadian Nyaris Cedera/KNC) atau Adverse Event (Kejadian Tidak Diharapkan/KTD) selanjutnya pengurangan kesalahan dapat dicapai dengan memodifikasi perilaku. Perawat harus melibatkan kognitif, afektif dan tindakan yang mengutamakan keselamatan pasien (Julia, 2016).

Laporan Insiden Keselamatan Pasien di Indonesia berdasarkan propinsi menemukan bahwa dari 145 insiden yang dilaporkan 55 kasus $(37,9 \%)$ terjadi di wilayah DKI Jakarta. Berdasarkan jenisnya dari 145 insiden yang dilaporkan didapatkan Kejadian Nyaris Cidera (KNC) sebanyak 69 kasus (47,6\%), Kejadian Tidak Diharapkan (KTD) sebanyak 67 kasus (46,2\%), dan lain-lain sebanyak 9 kasus (6,2\%). Walaupun data ini telah ada secara umum di Indonesia, kejadian atau catatan yang berhubungan dengan keselamatan pasien di rumah sakit belum dikembangkan secara menyeluruh oleh semua rumah sakit sehingga perhitungan kejadian yang berhubungan dengan keselamatan pasien masih sangat terbatas (Lumenta, 2008; Umaternate, Kumaat, \& Mulyadi, 2015).

Cahyono (2008) menyatakan setiap asuhan klinis baik terkait dengan proses diagnosis, terapi, tindakan pembedahan, pemberian obat, pemeriksaan laboratorium, dsb. dapat menimbulkan kerugian yang tidak diharapkan pasien baik secara fisik (cedera iatrogenik), finansial, maupun sosial. Secara lebih populer, asuhan klinis yang kemudian menimbulkan dampak yang merugikan bagi pasien akibat manajemen medis dan bukan akibat penyakit yang diderita pasien dikenal sebagai adverse events atau KTD (baik oleh dokter maupun pasien).

Keamanan pelayanan di rumah sakit salah satunya dimulai dari ketepatan identifikasi pasien. Kesalahan identifikasi pasien diawal pelayanan akan berdampak pada kesalahanan pelayanan pada tahap selanjutnya (WHO, 2009). Proses identifikasi pasien perlu dilakukan dari sejak awal pasien masuk rumah sakit yang kemudian identitas tersebut akan selalu dikonfirmasi dalam segala proses di rumah sakit, seperti saat sebelum memberikan obat, darah atau produk darah atau sebelum mengambil darah dan spesimen lain untuk pemeriksaan. Sebelum pengobatan dan tindakan atau prosedur. Hal ini dilakukan agar tidak terjadi kesalahan identifikasi pasien yang nantinya bisa berakibat fatal jika pasien menerima prosedur medis yang tidak sesuai dengan kondisi pasien seperti salah pemberian obat, salah pengambilan darah bahkan salah tindakan medis (Permenkes RI, 2017).

Ketepatan identifikasi pasien menjadi hal yang penting, bahkan berhubungan dengan keselamatan pasien. Kesalahan karena kekeliruan mengenai identitas pasien merupakan hal yang amat fatal dan berat hukumnya. Perlu proses kolaboratif untuk memperbaiki proses identifikasi untuk mengurangi kesalahan identifikasi pasien. Untuk mencegah terjadi kesalahan identifikasi pasien, perawat selaku tenaga kesehatan yang paling lama dan yang paling sering berinteraksi dan berjumpa dengan pasien harus berpengetahuan baik karena setiap tindakan yang dilakukan harus didasari dengan pengetahuan. Pengetahuan merupakan hal yang penting yang harus dimiliki sepenuhnya oleh perawat professional untuk mencegah terjadinya Kejadian Tidak Diharapkan 
(KTD), Kejadian Nyaris Cedera (KNC), Kejadian Potensial Cedera (KPC) (Anggraeni, 2014).

Guesthi et al, (2016) menemukan bahwa prevalensi keselamatan pasien di Rumah Sakit Umum Daerah Kota Bekasi dari bulan September 2015 sampai dengan Maret 2016 ditemukan sebanyak 12,1\% Kejadian Tidak Dihadarapkan (KTD), 42,3\% Kejadian Nyaris Cidera (KNC), 41,4\% Kejadian Potensial Cidera (KPC). Dari data tersebut Kejadian Nyaris Cedera (KNC) merupakan kejadian yang paling sering terjadi, 42,3\% Kejadian Nyaris Cidera (KNC) yang terjadi disebabkan oleh adanya kesalahan identifikasi pasien sebanyak 63,5\% (Hendro, 2012). Data insiden keselamatan pasien tahun 2012 melaporkan analisis penyebab terjadinya insiden $46 \%$ berkaitan dengan salah identifikasi, 36\% dikarenakan komunikasi yang tidak efektif sehingga terjadi medication error, $18 \%$ dikarenakan prosedur tidak dijalankan. Joint Commission International (WHO, 2012) menunjukkan bahwa sebanyak 13\% surgical error dan $68 \%$ transfusi darah terjadi karena kesalahanpada tahapan identifikasi pasien dari $68 \%$ kesalahan transfusi darah 11 orang diantaranya meninggal. Berdasarkan data yang peneliti dapatkan di Rumah Sakit Universitas Sumatera Utara mengenai ketepatan identifikasi pasien pasien periode Januari-Juni 2018 terdapat 39,3\% perawat tidak melakukan identifikasi sebelum melakukan tindakan/ prosedur, terdapat 38,7\% perawat tidak melakukan identifikasi sebelum pemberian obat, terdapat $40,2 \%$ perawat tidak melakukan identifikasi sebelum memberikan transfusi darah/ produk darah, terdapat 39,3\% perawat tidak melakukan identifikasi sebelum mengambil darah/spesimen, diruang rawat inap Mahoni, Meranti, Cendana dan Zaitun rumah sakit Universitas Sumatera Utara ditemukan bahwa belum optimalnya pelaksanaan identifikasi diruangan tersebut.

Pendidikan kesehatan pada hakekatnya adalah membantu agar individu dapat mengambil sikap yang bijaksana terhadap kesehatan dan kualitas hidup mereka WHO (2012) serta yang diharapkan tenaga kesehatan adalah perawat dan pasien memiliki pengetahuan yang cukup serta menerapkannya dalam kehidupan sehari-hari. Penyampaian pesan yang dilakukan dalam pendidikan kesehatan atau pelaksanaaan tidak hanya dilakukan dengan cara face to face, namun juga dapat dilakukan dengan menggunakan berbagai media. Dan dilihat dari efektif tidaknya bentuk atau metode pelaksanaaan kesehatan, media audio visual dirasa sangat tepat untuk menyampaikan pesan kepada pasien.

\section{METODE PENELITIAN}

Penelitian ini menggunakan metode quasi-experimen, dengan one group pretest and postest design. Data dikumpulkan dengan Menggunakan Kuesioner yang telah di validasi dan di nyatakan reliabel untuk digunakan, dibagikan kepada 120 orang pasien rawat inap di Rumah sakit Universitas Sumatera Utara. Data disajikan dalam distribusi frekwensi dan dianalisis secara deskriptif.

\section{Pelaksanaan Penyuluhan dengan Menggunakan Media Audio Visual}

Persiapan Pembuatan Media Audio Visual (Video) Pelaksanaan Identifikasi pasien. Persiapan yang dilakukan dalam pembuatan aplikasi media audio visual pelaksanaaan Identifikasi pasien adalah kamera yang digunakan untuk merekam video pembelajaran pelaksanaaan tentang pelaksanaan Identifikasi pasien. Alat perekam, yang digunakan untuk merekam audio untuk video pelaksanaaan tentang Identifikasi pasien. Laptop dan aplikasi edit video, yang digunakan untuk mengedit dan menyatukan video 
yang telah direkam. Scenario disusun bersumber pada Sasaran Keselamatan Pasien (Permenkes, 2017).

Pemeran sebagai: pasien, perawat, terlebih dahulu di latih untuk lebih memahami peran yang akan dimainkan. Seting dan latar disesuaikan dengan ruang rawat. Setelah semua alat yang dibutuhkan siap kemudian dilakukan pembuatan video pelaksanaaan tentang Identifikasi pasien, Video Bersurasi 5.6 menit.

\section{Kegiatan Pelaksanaan Penyuluhan dengan Menggunakan Media Audio Visual}

Kegiatan yang dilaksanakan dalam penyuluhan dengan menggunakan media audio visual adalah:

Memperoleh izin dari rumah sakit dan memberitahu kepada kepala ruangan untuk dilaksanakannya penyuluhan. Memperkenalkan diri dan menjelaskan tujuan kegiatan aplikasi media audio visual pelaksanaaan Identifikasi pasien kepada pasien. Mengkaji pengetahuan pasien dengan menggunakan kuesioner yang dibagikan satu per satu kepada pasien. Melakukan penyuluhan dengan menggunakan media audio visual (video) tentang pelaksanaan Identifikasi pasien: menggunakan laptop dan speaker. 1 hari setelah penyuluhan selesai, peneliti kembali membagikan kuesioner yang sama kepada pasien untuk mengetahui pengetahuan pasien setelah terpapar penyuluhan dengan menggunakan media audio visual (video).

\section{HASIL PENELITIAN}

Tabel.1

Distribusi Frekuensi Usia dan Jenis Kelamin Pasien yang Mengikuti Penyuluhan Pelaksanaan Identifikasi Pasien

\begin{tabular}{lcc}
\hline Karakteristik & Frekwensi & Persentase \\
\hline Usia & & \\
$20-29$ & 8 & 6.7 \\
$30-39$ & 56 & 46.6 \\
$40-49$ & 36 & 30.0 \\
$50-59$ & 20 & 16.7 \\
Jenis kelamin & & \\
laki-laki & 40 & 33.3 \\
perempuan & 80 & 66.7 \\
$\quad$ Total & 120 & 100 \\
\hline
\end{tabular}

Hasil penelitian menunjukkan bahwa pasien paling banyak berada pada kelompok usia 30-39 tahun yaitu sebanyak 56 orang, dan pasien perempuan ada sebanyak 80 orang. 
Tabel. 2

Distribusi Frekuensi Kategori Pengetahuan Pasien Sebelum Diberikan Penyuluhan Pelaksanaan Identifikasi Pasien Menggunakan Media Audiovisual

\begin{tabular}{lcc}
\hline \multicolumn{1}{c}{ Kategori Pengetahuan } & Frekuensi (n) & Persentase (\%) \\
\hline Baik & 0 & 0 \\
Cukup & 40 & 33,3 \\
Kurang & 80 & 66,7 \\
\hline Total & 120 & 100 \\
\hline
\end{tabular}

Berdasarkan skor jawaban yang diberikan pada tiap pertanyaan dalam kuesioner, diperoleh kategori pengetahuan pasien sebelum penyuluhan adalah tidak ada pasien dalam kategori pengetahuan baik, sebanyak 40 orang pasien dalam kategori pengetahuan cukup.

Tabel. 3

Distribusi Frekuensi Jawaban Pasien Sebelum Diberikan Penyuluhan Pelaksanaan Identifikasi Pasien Menggunakan Media Audiovisual

\begin{tabular}{lcccc}
\hline \multirow{2}{*}{ Instrumen } & \multicolumn{2}{c}{ Benar } & \multicolumn{2}{c}{ Salah } \\
\cline { 2 - 5 } & Frekuensi (n) & Persentase (\%) & Frekuensi (n) & Persentase (\%) \\
\hline Pertanyaan 1 & 44 & 36,7 & 76 & 63,3 \\
Pertanyaan 2 & 12 & 10 & 108 & 90 \\
Pertanyaan 3 & 52 & 43,3 & 68 & 56,7 \\
Pertanyaan 4 & 28 & 23,3 & 92 & 76,7 \\
Pertanyaan 5 & 32 & 26,7 & 88 & 73,3 \\
Pertanyaan 6 & 40 & 33,3 & 80 & 66,7 \\
Pertanyaan 7 & 48 & 40 & 72 & 60 \\
Pertanyaan 8 & 20 & 16,7 & 100 & 83,3 \\
Pertanyaan 9 & 44 & 36,7 & 76 & 63,3 \\
Pertanyaan 10 & 12 & 10 & 108 & 90 \\
\hline
\end{tabular}

Hasil penelitian ini memberikan Informasi bahwa sebanyak 108 orang pasien memberikan jawaban yang salah terhadap warna gelang untuk pasien laki-laki (pertanyaan No: 10), dan sebanyak 52 orang menjawab dengan benar pertanyaan tentang tujuan Pelaksanaan Identifikasi pasien (pertanyaan No: 3).

Tabel. 4

Distribusi Frekuensi Kategori Pengetahuan Pasien Setelah Diberikan Penyuluhan Pelaksanaan Identifikasi dengan Menggunakan Media Audiovisual

\begin{tabular}{lcc}
\hline \multicolumn{1}{c}{ Kategori Pengetahuan } & Frekuensi (n) & Persentase $(\%)$ \\
\hline Baik & 12 & 10 \\
Cukup & 68 & 56,7 \\
Kurang & 40 & 33,3 \\
\hline Total & 120 & 100 \\
\hline
\end{tabular}


Berdasarkan skor jawaban yang diberikan pasien setelah mendapatkan penyuluhan dengan menggunakan media audiovisual (video), sebanyak 12 orang pasien dinyatakan masuk dalam kategori pengetahuan baik, dan 68 orang pasien dalam kategori pengetahuan cukup.

Tabel. 5

Distribusi Frekuensi Jawaban Pasien Setelah Diberikan Penyuluhan Pelaksanaan Identifikasi Pasien Menggunakan Media Audiovisual

\begin{tabular}{ccccc}
\hline Instrumen & \multicolumn{2}{c}{ Benar } & \multicolumn{2}{c}{ Salah } \\
\cline { 2 - 5 } & $\begin{array}{c}\text { Frekuensi } \\
(\mathrm{n})\end{array}$ & $\begin{array}{c}\text { Persentase } \\
(\%)\end{array}$ & $\begin{array}{c}\text { Frekuensi } \\
(\mathrm{n})\end{array}$ & $\begin{array}{c}\text { Persentase } \\
(\%)\end{array}$ \\
\hline Pertanyaan 1 & 64 & 53,3 & 56 & 46.7 \\
Pertanyaan 2 & 64 & 53,3 & 56 & 46.7 \\
Pertanyaan 3 & 64 & 53,3 & 56 & 46.7 \\
Pertanyaan 4 & 64 & 53,3 & 56 & 46.7 \\
Pertanyaan 5 & 64 & 53,3 & 56 & 46.7 \\
Pertanyaan 6 & 52 & 43,4 & 68 & 56,7 \\
Pertanyaan 7 & 80 & 66,7 & 40 & 33,3 \\
Pertanyaan 8 & 92 & 76,7 & 28 & 23.3 \\
Pertanyaan 9 & 64 & 53.3 & 56 & 46.7 \\
Pertanyaan 10 & 100 & 83.37 & 20 & 16.7 \\
\hline
\end{tabular}

Dari hasil penelitian diperoleh bahwa sebanyak 100 orang pasien menjawab dengan benar warna gelang untuk pasien laki-laki (pertanyaan No: 10), dan sebanyak 68 orang pasien memberikan Jawaban yang salah untuk pertanyaan tentang waktu pelaksanaan identifikasi (pertanyaan No:6).

\section{PEMBAHASAN}

Hasil penelitian menunjukkan bahwa pasien sebelum mendapatkan penyuluhan adalah 40 orang pasien dalam kategori pengetahuan cukup dan 80 orang pasien dalam kategori pengetahuan kurang. Setelah dilakukan penyuluhan dengan menggunakan media audiovisual jumlah pasien dalam kategori pengetahuan mengalami peningkatan, hal ini dapat dilihat sebanyak 12 orang pasien masuk dalam kategori pengetahuan baik, yang sebelumnya tidak ada pasien yang dikategorikan memiliki pengetahuan baik. 68 orang pasien dikategorikan dalam pengetahuan cukup. Hasil ini menunjukkan Adanya perbedaan jumlah pasien dalam kategori pengetahuannya sebelum dan sesudah diberikan penyuluhan tentang pelaksanaan identifikasi pasien dengan menggunakan media audiovisual.

Hal tersebut dapat diasumsikan bahwa, penyuluhan tentang pelaksanaan identifikasi pasien yang diberikan tersampaikan dengan baik kepada pasien, sehingga terjadi peningkatan kategori pengetahuan pasien. Penyuluhan kesehatan adalah penambahan pengetahuan dan kemampuan seseorang melalui teknik praktik belajar atau instruksi dengan tujuan mengubah atau mempengaruhi perilaku manusia baik secara individu, kelompok maupun perawat dan pasien untuk meningkatkan kesadaran akan nilai kesehatan sehingga dengan sadar mau mengubah perilakunya menjadi perilaku 
hidup sehat (Simamora, 2019).

Hasil penelitian ini didukung oleh penelitian Kumboyono (2011) tentang perbedaan efek pendidikan kesehatan menggunakan media cetak dengan media audiovisual terhadap peningkatan pengetahuan pasien tuberculosis. Hasil penelitian menunjukan bahwa media video mampu meningkatkan pengetahuan pasien. Hal ini juga sependapat dengan penelitian yang dilakukan oleh Saraswati (2011) menyatakan bahwa penyuluhan dengan media video mampu meningkatkan pengetahuan dan partisipasi lebih tinggi terhadap pengetahuan tentang kanker serviks di wilayah Surakarta.

Menurut Contento (2007) menyatakan bahwa video yang ditambahkan dalam pesan verbal dapat meningkatkan motivasi untuk menerima pesan dan mengingatnya dengan lebih baik karena media video menawarkan penyuluhan yang lebih menarik dan tidak menoton dengan menampilkan gerak, gambar dan suara sehingga orang yang melihatnya mempunyai keingintahuan terhadap isi video yang diharapkan dapat menyerap informasi dan mengimplementasikannya dalam perilaku dan gaya hidup sehari-hari. Hasil penelitian ini juga didukung oleh penelitian Kristina Blandina Wea (2014) mengenai "Pendidikan Kesehatan dengan Media Audio Visual meningkatkan perilaku Ibu dalam Penanganan Infeksi Saluran Pernafasan Akut pada Balita di Kelurahan Lebijaga Kabupaten Ngada" menunjukkan adanya perbedaan pengetahuan yang signifikan antara sebelum dan sesudah diberikan pendidikan kesehatan dengan media audio visual dengan media audio visual adanya perbandingan tingkat pengetahuan pasien yang tidak mendapatkan pendidikan kesehatan dengan media audio visual.

Pengetahuan dapat dipengaruhi oleh beberapa faktor, salah satunya yaitu usia. Usia dapat mempengaruhi pengetahuan seseorang, karena semakin bertambahnya usia maka semakin berkembang pula daya tangkap dan pola pikir seseorang sehingga pengetahuan yang diperoleh pun semakin baik. Namun terjadi penurunan daya tangkap pada usia lanjut yang dipengaruhi oleh faktor fisiologis sehingga tingkat pengetahuan yang dimilikipun juga mengalami penurunan. Dalam penelitian ini usia yang paling banyak adalah pada kelompok usia 30-39 tahun, merupakan usia matang, dimana seseorang pada umur tersebut akan memiliki pola tangkap dan daya pikir yang baik sehingga pengetahuan yang dimilikinya juga akan semakin membaik. Akan Maulana (2007) menyatakan bahwa ada 6 faktor fisik yang dapat menghambat proses belajar pada orang dewasa diantaranya gangguan penglihatan dan pendengaran sehingga membuat penurunan pada suatu waktu dalam kekuatan berfikir dan bekerja.

Seiring bertambahnya usia seseorang maka bertambah pula pengalaman seseorang yang melibatkan panca indra yang dapat mempengaruhi pengetahuan (Simamora, 2017). Hal ini sesuai dengan teori yang mengatakan semakin cukup usia seseorang maka tingkat kematangan dan kekuatan seseorang akan lebih matang dalam berfikir. Bertambahnya usia seseorang dapat berpengaruh pada bertambahnya pengetahuan yang diperoleh, tetapi pada usia-usia tertentu atau menjelang usia lanjut kemampuan penerimaan atau pengingatan suatu pengetahuan akan berkurang (Hendro, 2012). Usia akan memberikan gambaran pengalaman yang telah dilaluinya. Pengalaman merupakan guru yang terbaik (experience is the best teacher), pepatah tersebut bisa diartikan bahwa pengalaman merupakan sumber pengetahuan, atau pengalaman itu merupakan cara untuk memperoleh suatu kebenaran pengetahuan. Oleh sebab itu pengalaman pribadi pun dapat dijadikan sebagai upaya untuk memperoleh pengetahuan. Hal ini dilakukan 
dengan cara mengulang kembali pengetahuan yang diperoleh dalam memecahkan persoalan yang dihadapai pada masa lalu Pada penelitian ini pasien lebih banyak perempuan Menurut hasil penelitian yang dilakukan oleh peneliti, mayoritas yang mau mengikuti penyuluhan adalah perempuan. Pada dasarnya perempuan biasanya lebih rajin dari pada laki-laki, contohnya dalam mengikuti suatu pelatihan atau seminar sehingga memungkinkan perempuan memiliki pengetahuan yang lebih baik dan berkembang dari pada laki-laki. Jenis kelamin sangat mempengaruhi partisipasi, partisipasi yang dilakukan oleh seorang laki-laki akan berbeda dengan partisipasi yang dilakukan oleh perempuan. Hal ini disebabkan karena adanya sistem pelapisan sosial yang terbentuk dalam responden yang membedakan kedudukan dan derajat laki-laki dan perempuan, sehingga dapat menimbulkan perbedaan-perbedaan hak dan kewajiban (Simamora, 2017).

Pengetahuan atau kognitif merupakan domain yang sangat penting dalam membentuk tindakan seseorang (overt behaviour). Dalam penelitian ini masih ada 40 orang pasien yang dikategorikan dalam pengetahuan kurang. Hasil ini dapat terjadi karena dipengaruhi oleh kondisi pasien saat dilakukan penyuluhan, kondisi akan mempengaruhi minat pasien dalam menyimak penyuluhan yang diberikan. Hayati (2007) menyatakan bahwa minat berhubungan dengan pengetahuan seseorang. Semakin tinggi minat seseorang terhadap suatu hal, maka akan semakin tinggi tingkat pengetahuannya. Menurut Slameto (2010) minat adalah suatu rasa lebih suka dan rasa ketertarikan pada suatu hal atau aktivitas, tanpa ada yang menyuruh. Minat pasien harus ditumbuhkan agar pasien dapat bekerja sama selama menjalani perawatan di rumah sakit, untuk itu, perlu memberikan motivasi dalam bentuk beragam agar tercipta suasana dan kondisi yang sama sama menguntungkan, baik untuk pasien maupun buat petugas kesehatan yang memberikan layanan asuhan.

\section{SIMPULAN}

Penyuluhan yang diberikan dengan menggunakan media audiovisual dapat meningkatkan pengetahuan pasien di rumah sakit Universitas Sumatera Utara. Media audiovisual merupakan salah satu media yang baik untuk digunakan sebagai media dalam penyuluhan kesehatan karena melibatkan pendengaran dan penglihatan sekaligus dalam satu proses atau kegiatan.

\section{SARAN}

Kepada peneliti selanjutnya agar melakukan analisis hasil penelitian dengan mengunakan uji statistik agar dapat diketahui nilai pengaruh perlakuan yang diberikan.

\section{DAFTAR PUSTAKA}

Anggraini.(2014).Evaluasi Pelaksanaan Sistem Identifikasi Pasien di Insalasi Rawat Inap Rumah Sakit. Jurnal Kedokteran Brawijaya, 28, 99-103. Retrieved 20 Agustus 2019 , Fromhttp://jkb.ub.ac.id/index.php/jkb/article/download/529/406.pdf

Australian on Safety and Quality in Health Care. (2008). Australian Commission Onsafety and Quality in Health Care. Retrieved Agustus,20, 2019, Fromhttps://www.safetyandquality/windows/into/safetyandqualityin/health.pdf

Blandina, W. K. (2014)Pengaruh Pendidikan Kesehatan dengan Media Audio Visual terhadap Perilaku Ibu dalam Penanganan Infeksi Saluran Pernafasan Akut pada 
Balita di Kelurahan Lebijaga Kabupaten Ngada. Retrieved, 20 Juli 2019. From: https://docplayer.info/79699840-Adln-perpustakaan-universitas-airlanggaskripsi.html

Cahyono. (2008). Membangun Budaya Keselamatan. Yogyakarta: Kanisius

Contento, I. R. (2007). Nutrition Education: Linking Research, Theory, and Practice. Sudbury: Jones and Barlett Publishers

Hayati, R. N. (2007). Pengaruh Pengetahuan, Sikap dan Motivasi terhadap Minat Bidan Mengikuti Uji Kompetensi di Kota Semarang Tahun 2007. Tesis. Program Pascasarjana Universitas Diponegoro. Semarang. Retrieved 20 Juni 2019 file:///C:/Users/sony/Downloads/78-49-149-1-10-20170216.pdf

Hendro. (2012). Hubungan Pengetahuan Perawat dengan Penerapan Identify Patient Correctly di RSUP Ratatotok Buyat Kabupaten Minahasa Tenggara. Retrieved 20 Juni 2019, From: http://media.neliti.com/media/piblications/105324-IDhubungan-perawat-dengan-pene.pdf

Joint Commision International. (2017). Joint Commission International Accreditation Standards for Hospital (8th ed.). USA: Department of Publication Joint Commission Resource

Joint Commision International. (2013). Joint Commission International Accreditation Standards for Hospital (5thed.). USA: Department of Publication Joint Commission Resource

Julia, R., Michael, K \& Angelita, L. (2016). Hubungan Perilaku dengan Kemampuan Perawat dalam Melaksanakan Keselamatan Pasien (Patient Safety) di Ruang IGD. Journal Keperawatan, 4(2). Retrieved Agustus 20, 2019, From perilaku-dengankemampuan-perawat.pdf

KARS. (2017). Intrumen Akeditasi Rumah Sakit versi 2012. Jakarta

Lumenta, N. A. (2008). State of the Art Patient Safety. Disampaikan pada Workshop Keselamatan Pasien dan Manajemen Resiko Klinis di RSAB Harapan Kita pada tanggal 1-3 April 2008. Jakarta: Tidak dipublikasikan

Kumboyono. (2011). Perbedaan Penyuluhan Kesehatan Menggunakan Media Cetak dengan Media Audio Visual terhadap Peningkatan Pengetahuan Pasien Tuberkulosis. Skripsi. Sekolah Tinggi Ilmu Kesehatan Muhammadyah, Gombong.

Maulana, H.( 2007). Promosi Kesehatan. Jakarta: Penerbit Buku Kedokteran EGC

Permenkes. (2017). Permenkes No 11 Tahun 2017 tentang Keselamatan Pasien. Jakarta

Saraswati. (2011). Pengaruh Promosi Kesehatan terhadap Pengetahuan dan Partisipasi Wanita dalam Deteksi Dini Kanker Serviks. Tesis. Pasca sarjana. Universitas Sebelas Maret Surakarta. Retrieved July 22, 2019 from: http://eprints.ums.ac.id/39799/12/NASKAH\%20PUBLIKASI.pdf

Simamora, R H. (2017). A Strengthening of Role of Health Cadres in BTA-Positive Tuberculosis (TB) Case Invention Throught Education with Module Development and Video Approaches in Medan Padang Bulan Center, North Sumatera Indonesia

Simamora, R. H., Saragih, E. (2019). Penyuluhan Kesehatan terhadap Masyarakat: Perawatan Penderita Asam Urat dengan Media Audiovisual. JPPM (Jurnal Pendidikan dan Pemberdayaan Masyarakat ), 6(1), 24-31

Slameto. (2010). Belajar dan Faktor-Faktor yang Mempengaruhi. Jakarta: Rineka Cipta SNARS. (2017). Standar Nasional Akreditasi Rumah Sakit, (ed.1). Jakarta

Umaternate, T. S., Kumaat, L. T., Mulyadi. (2015). Hubungan Pelaksanaan Identifikasi Pasien Secara Benar dengan Kepuasan Pasien di Instalasi Gawat Darurat (IGD) 
RSUP. Prof, DR. A. D. Kandou Manado. E-Journal Keperawatan (e-Kp), 3(2),1-6 World Health Organization \& Joint Comission International. (2009). Communication during patient hand-overs. Retrieved July 22, 2019, fromhttp://www.who.int/patientsafety/solutions/patientsafety/PSSolution3.pdf

World Health Organization. (2012). Patient Safety Culture Retrieved July 22, 2019, fromhttp://www.who.int/patientsafety/solutions/patientsafety/PSSolution3.pdf 